CARTA AL EDITOR

\section{SÍNDROME INFLAMATORIO MULTISISTÉMICO PEDIÁTRICO ASOCIADO A COVID-19: REPORTE PRELIMINAR DE UN HOSPITAL DEL PERÚ}

\section{PEDIATRIC MULTISYSTEMIC INFLAMMATORY SYNDROME ASSOCIATED WITH COVID-19: PRE- LIMINARY REPORT OF A HOSPITAL IN PERU}

\author{
Olguita del Aguila (1),a, Jesús Domínguez-Rojas (10,b, \\ Raquel Garcés-Ghilardi(i)2,c, Matilde Estupiñan-Vigil(102,c, \\ Giancarlo Alvarado-Gamarra ${ }^{2, c}$ \\ 1 Servicio de Pediatría de Especialidades Clínicas, Hospital Nacional \\ Edgardo Rebagliati Martins, Lima, Perú. \\ 2 Servicio de Pediatría Clínica, Hospital Nacional Edgardo Rebagliati \\ Martins, Lima, Perú \\ a Infectóloga pediatra; ${ }^{\mathrm{b}}$ pediatra intensivista; ${ }^{\mathrm{c}}$ médico pediatra.
}

Sr. Editor: La infección por SARS-CoV-2 en pediatría tiene un comportamiento clínico distinto a los adultos. Solo un 5\% son casos graves y menos del $1 \%$ son críticos ${ }^{(1)}$. Además, se ha descrito el síndrome inflamatorio multisistémico pediátrico asociado a COVID-19 (SIM-P) que puede causar falla multiorgánica y la muerte. Se reportó inicialmente en los Estados Unidos e Inglaterra, y luego en Europa ${ }^{(2)}$. En Latinoamérica existen pocos reportes ${ }^{(3)}$. Probablemente es secundario a una reacción inmunológica posviral, con aumento de casos entre las cuatro a seis semanas luego del pico por SARS-CoV-2. Un gran porcentaje ha requerido manejo por una unidad de cuidados intensivos $(\mathrm{UCI})^{(2)}$. En el Perú existen varios centros que atienden el SIM-P, pero hasta el momento sólo se ha reportado una serie de casos de ocho pacientes ${ }^{(4)}$. Por lo tanto, con el objetivo de describir el perfil clínico-epidemiológico, mejorar su manejo, y disminuir su morbimortalidad; reportamos los resultados preliminares de 37 casos de SIM-P del Hospital Nacional Edgardo Rebagliati Martins (HNERM), en Lima, Perú, desde abril a agosto del 2020.

Para el diagnóstico se usaron los criterios de la Organización Mundial de la Salud, Royal College of Paediatrics and Child Health de Reino Unido, y/o Centers for Disease Control and Prevention de los Estados Unidos ${ }^{(2)}$, que consideran fiebre, marcadores inflamatorios alterados, disfunción orgánica y excluir otras causas. Se recolectó la información retrospec-

\footnotetext{
Citar como: del Aguila O, Domínguez-Rojas J, Garcés-Ghilardi R, EstupiñanVigil M, Alvarado-Gamarra G. Síndrome inflamatorio multisistémico pediátrico asociado a COVID-19: reporte preliminar de un hospital del Perú. Rev Peru Med Exp Salud Publica. 2021;38(1):180-2. doi: https://doi.org/10.17843/ rpmesp.2021.381.6460
}

Correspondencia: Olguita del Aguila; Jr. Abraham Valdelomar Nº654 Dpto 304 Urbanización El Carmen, Pueblo Libre, Lima, Perú; odaguila@hotmail.com

Recibido: 15/09/2020 Aprobado: 28/10/2020 En línea: 29/01/2021 tivamente. El proyecto fue aprobado por el Comité de Ética en Investigación para COVID-19 del Seguro Social de Salud, y por el Comité Institucional de Ética en Investigación del HNERM.

La mediana de edad fue de 8 años, 25 (67,6\%) fueron de sexo masculino, y 9 (24,3\%) tuvieron comorbilidad. La mayoría presentaba prueba molecular negativa e IgG positiva. Del total, $18(48,6 \%)$ presentaron criterios para enfermedad de Kawasaki (EK), 8 (21,6\%) shock, y 11(29,8\%) para fiebre con marcadores inflamatorios alterados, pero sin shock ni EK. La disfunción orgánica se presentó en 16 (43,2\%) pacientes, predominando la falla cardiovascular y respiratoria. Asimismo, 15 (40,5\%) requirieron ingreso a una UCI, y 11 $(29,7 \%)$ ventilación mecánica invasiva (VMI). La disfunción orgánica, el ingreso a UCI y a VMI fue más frecuente en el subgrupo con shock (87,5\%). Del total, 36 (97,3\%) requirieron inmunoglobulina intravenosa (IVIG) a $2 \mathrm{~g} / \mathrm{kg}$, y 10 $(27,0 \%)$ una segunda dosis. En el subgrupo con EK un mayor porcentaje $(38,9 \%)$ requirió una segunda dosis de IVIG. Del total, la mayoría recibió ácido acetilsalicílico (AAS) (89,2\%) y antibióticos (72,9\%) al inicio y $21(56,8 \%)$ recibieron corticoides (a $2 \mathrm{mg} / \mathrm{kg} /$ día en la mayoría). Se administró enoxaparina, ivermectina e hidroxicloroquina en menor porcentaje, estos dos últimos al inicio de la pandemia. Se realizó ecocardiografía a $30(81,1 \%)$ pacientes, evidenciándose aneurisma de las arterias coronarias en $5(16,7 \%)$. Fallecieron dos pacientes, la letalidad fue de 5,4\% (2/37). Estos pertenecían al subgrupo de shock, por lo que la letalidad aumento a $25,0 \%$ (2/8) en este subgrupo (Tabla 1$)$.

El SIM-P tiene características similares a la EK o al sindrome de shock tóxico. Sin embargo, posee características propias como una mayor afectación de escolares, de niños africanos o hispanos, mayor alteración de los marcadores inflamatorios y compromiso cardiovascular difuso ${ }^{(2)}$. La edad de presentación es similar a otras series, predominando en varones. La mayoría presentaba prueba molecular negativa e IgG positiva, similar a lo descrito en otros estudios; aunque se ha reportado un tercio de los casos positivos por reacción en cadena de polimerasa (PCR). Esto refuerza la hipótesis de un síndrome posviral no mediado por invasión viral directa, sino que coincide con el desarrollo de respuestas inmunitarias adquiridas al SARS-CoV-2 ${ }^{(2)}$. En otras series un gran porcentaje ha requerido ingreso a una UCI, en nuestro hospital esto solo ocurrió en el $41 \%$, el resto requirió manejo en una unidad no crítica pero con monitoreo, sobre todo en aquellos con fenotipo de síndrome febril con marcadores inflamatorios alterados.

Por otro lado, no existen estudios que comparen la eficacia de los tratamientos. Existen algunas guías y recomendaciones que sugieren soporte respiratorio, hemodinámico, y tratamiento del proceso inflamatorio con IVIG, corticoides, AAS, e inmunomoduladores de segunda línea. También sugieren anticoagulación para casos específicos, y los anti- 
Tabla 1. Características epidemiológicas, clínicas y de tratamiento del síndrome inflamatorio multisistémico pediátrico asociado a COVID-19 (SIM-P). Hospital Nacional Edgardo Rebagliati Martins, Lima, Perú, abril-agosto del 2020.

\begin{tabular}{|c|c|c|c|c|}
\hline Características & $\begin{array}{l}\text { SIM-P } \\
(\mathbf{n}=37)\end{array}$ & $\begin{array}{l}\text { Fiebre e inflamación } \\
\qquad(n=11)^{a}\end{array}$ & $\begin{array}{c}\text { Con shock } \\
(n=8)^{b}\end{array}$ & $\begin{array}{l}\text { Con EK } \\
(\mathbf{n}=18)^{\mathrm{c}}\end{array}$ \\
\hline Edad, mediana (RIC) & $8(4-10)$ & $8(3-10)$ & $8(4,5-9,5)$ & $7(4-10)$ \\
\hline \multicolumn{5}{|l|}{ Sexo } \\
\hline Masculino & $25(67,6)$ & $6(54,6)$ & $6(75,0)$ & $13(72,2)$ \\
\hline Femenino & $12(32,4)$ & $5(45,4)$ & $2(25,0)$ & $5(27,8)$ \\
\hline \multicolumn{5}{|l|}{ Virología } \\
\hline RT-PCR COVID-19 & $3(8,1)$ & $0(0,0)$ & $3(37,5)$ & $0(0,0)$ \\
\hline IgG COVID-19 & $26(70,3)$ & $7(63,6)$ & $7(87,5)$ & $12(66,7)$ \\
\hline IgM COVID-19 & $6(16,2)$ & $2(18,2)$ & $2(25,0)$ & $2(11,1)$ \\
\hline No se realizó RT-PCR & $4(10,8)$ & $1(9,1)$ & $0(0,0)$ & $3(16,7)$ \\
\hline Comorbilidad & $9(24,3)$ & $3(27,3)$ & $5(62,5)$ & $1(5,6)$ \\
\hline UCI & $15(40,5)$ & $2(18,2)$ & $7(87,5)$ & $6(33,3)$ \\
\hline VM & $11(29,7)$ & $1(9,1)$ & $7(87,5)$ & $3(16,7)$ \\
\hline $\mathrm{CAF}$ & $4(10,8)$ & $1(9,1)$ & $1(12,5)$ & $2(11,1)$ \\
\hline SAM & $2(5,4)$ & $1(9,1)$ & $0(0,0)$ & $1(5,6)$ \\
\hline Disfunción orgánica & $16(43,2)$ & $4(36,4)$ & $7(87,5)$ & $5(27,8)$ \\
\hline \multicolumn{5}{|l|}{ Tratamiento } \\
\hline IVIG & $36(97,3)$ & $11(100,0)$ & $7(87,5)$ & $18(100,0)$ \\
\hline Segunda infusión IVIG & $10(27,0)$ & $1(9,1)$ & $2(25,0)$ & $7(38,9)$ \\
\hline Corticoides & $21(56,8)$ & $5(45,5)$ & $6(75,0)$ & $10(55.6)$ \\
\hline AAS & $33(89,2)$ & $10(90,9)$ & $5(62,5)$ & $18(100,0)$ \\
\hline Antibióticos & $27(72,9)$ & $7(63,6)$ & $8(100,0)$ & $12(66,7)$ \\
\hline Enoxaparina & $4(10,8)$ & $0(0,0)$ & $1(12,5)$ & $3(16,7)$ \\
\hline Profilaxis & $1(2,7)$ & $0(0,0)$ & $0(0,0)$ & $1(5,6)$ \\
\hline Tratamiento & $3(8,1)$ & $0(0,0)$ & $1(12,5)$ & $2(11,1)$ \\
\hline Ivermectina & $7(18,9)$ & $2(18,2)$ & $4(50,0)$ & $1(5,6)$ \\
\hline Hidroxicloroquina & $4(10,8)$ & $1(9,1)$ & $2(25,0)$ & $1(5,6)$ \\
\hline Aneurisma coronario $^{\mathrm{d}}$ & $5 / 30(16,7)$ & $2 / 8(25,0)$ & $1 / 8(12,5)$ & $2 / 14(14,3)$ \\
\hline Muerte & $2(5,4)$ & $0(0,0)$ & $2(25,0)$ & $0(0,0)$ \\
\hline
\end{tabular}

SIM-P: síndrome inflamatorio multisistémico pediátrico asociado a COVID-19; EK: enfermedad de Kawasaki; RIC: rango intercuartil; RT-PCR: reacción en cadena de polimerasa en tiempo real; UCI: unidad de cuidados intensivos; VM: ventilación mecánica; CAF: cánula de alto flujo; SAM: síndrome de activación macrofágica; IVIG: inmunoglobulina intravenosa; AAS: ácido acetilsalicílico.

Las características se resumen en frecuencias y porcentajes. El SIM-P se divide en pacientes con fiebre e inflamación, con shock y con EK.

a Incluye el SIM-P que no cumple criterios de shock o de EK.

b Shock se definió como la necesidad de soporte con inotropo/vasopresor o reanimación de fluidos $>20 \mathrm{ml} / \mathrm{kg}$.

c Incluye casos de EK completo e incompleto según la American Heart Association.

¿ De los 37 casos sólo se realizó ecocardiografía a 30 pacientes.

bióticos se utilizan para tratar la potencial sepsis ${ }^{(5,6)}$. El uso de IVIG y AAS en gran porcentaje es debido a que un $49 \%$ de pacientes tuvieron el fenotipo de EK usando AAS a dosis altas $(50 \mathrm{mg} / \mathrm{kg} / \mathrm{día})$, y luego a dosis antiagregante. Además, se usó la dosis antiagregante en la mayoría de los casos de SIM-P. En otros países se usaron otros inmunomoduladores. En nuestro hospital no disponemos de anakinra e in- fliximab, y no se ha usado tocilizumab hasta el momento, tampoco disponemos de dosaje de IL-6.

En conclusión, en nuestro hospital la mediana de edad de niños con SIM-P fue 8 años, el 24,3\% tuvo alguna comorbilidad y la mayoría tuvo prueba molecular negativa e IgG positiva. Casi la mitad presentó criterios para EK. Al menos la tercera parte requirió VMI, internamiento en UCI y tuvo 
disfunción orgánica con una letalidad elevada (5,4\%). Esto se intensificó en el subgrupo con shock, aumentando su letalidad a $25 \%$. Por tanto, es necesario una vigilancia activa e implementación de UCI pediátricas y unidades de cuidados especiales. Con un diagnóstico y manejo precoz contribuiremos en gran medida con un mejor pronóstico de estos pacientes.

Contribuciones de los autores: ODA y GAG participaron en la concepción de la carta al editor, recolección de datos, análisis de datos, redacción y aprobación de la versión final. MEV, RGG y JDR participaron en la recolección de datos, redacción.

Financiamiento: Autofinanciado.

Conflictos de interés: Los autores declaran no tener conflictos de interés.

\section{REFERENCIAS BIBLIOGRÁFICAS}

1. Dong Y, Mo X, Hu Y, Qi X, Jiang F, Jiang Z, et al. Epidemiology of COVID-19 Among Children in China. Pediatrics. 2020;145(6): e20200702. doi:10.1542/peds.2020-0702.
2. Jiang L, Tang K, Levin M, Irfan O, Morris SK, Wilson K, et al. COVID-19 and multisystem inflammatory syndrome in children and adolescents [published online ahead of print, 2020 Aug 17]. Lancet Infect Dis. 2020; S1473-3099(20)30651-4. doi:10.1016/S1473-3099(20)30651-4.

3. Ulloa-Gutiérrez R, Ivankovich-Escoto G, Yamazaki-Nakashimada M. Síndrome inflamatorio multisistémico asociado a COVID-19 en niños y adolescentes: un llamado al diagnóstico. Rev Chil Infectol. 2020;37(3):199201. doi: $10.4067 / \mathrm{s} 0716-10182020000300199$.

4. De Coll-Vela LE, Zamudio-Aquise MK, Nuñez-Paucar H, Bernal-Mancilla RR, Schult-Montoya SC, Ccorahua-De La Paz M. Síndrome inflamatorio multisistémico asociado a COVID-19 en niños: serie de casos en un hospital pediátrico de Perú. Rev Peru Med Exp Salud Publica. 2020;37(3):559-65. doi: doi: 10.17843/rpmesp.2020.373.6126.

5. Henderson LA, Canna SW, Friedman KG, Gorelik M, Lapidus SK, Bassiri $\mathrm{H}$, et al. American College of Rheumatology Clinical Guidance for Pediatric Patients with Multisystem Inflammatory Syndrome in Children (MIS-C) Associated with SARS-CoV-2 and Hyperinflammation in COVID-19. Version 1 [published online ahead of print, 2020 Jul 23]. Arthritis Rheumatol. 2020;10.1002/art.41454. doi:10.1002/art.41454.

6. Centers for Disease Control and Prevention. Multisystem inflammatory syndrome. 2020. (acceso 7 de setiembre, 2020). Disponible en: https://www.cdc.gov/mis-c/hcp/. 